\title{
Metodologias Ativas e Experiências em Disciplinas Relacionadas à Área de Segurança do Trabalho
}

\author{
Eric Gabriel Oliveira Rodrigues* \\ *Instituto Santos Dumont, Instituto Internacional de Neurociências Edmond e Lily Safra, Brasil. \\ E-mail: ericgabriel.rodrigues@hotmail.com. \\ Ariana Mahara Fernandes Nery \\ •Escola de Engenharia e Tecnologia da Informação, Universidade Potiguar, Brasil. \\ E-mail: mahfern12@gmail.com. \\ Jemima Tabita Ferreira de Sousa \\ `Escola de Engenharia e Tecnologia da Informação, Universidade Potiguar, Brasil. \\ E-mail: jemima.tabita@gmail.com. \\ Vanessa Milena Mendes dos Santos` \\ `Escola de Engenharia e Tecnologia da Informação, Universidade Potiguar, Brasil. \\ E-mail: vanessamilena3@hotmail.com.
}


Aline Ferreira de Lima $^{\circ}$

${ }^{\circ}$ Escola de Engenharia e Tecnologia da Informação, Universidade Potiguar, Brasil. E-mail: alinelima789@outlook.com.

Kéricles Pinheiro de Oliveira*

${ }^{*}$ Escola de Engenharia e Tecnologia da Informação, Universidade Potiguar, Brasil.

E-mail: kericles_pinheiro@hotmail.com.

Cláudia Patrícia Torres Cruz

Escola de Engenharia e Tecnologia da Informação, Universidade Potiguar, Brasil. E-mail: claudiacruz.unp@gmail.com.

\title{
Resumo
}

O Aprendizado Baseado em Equipe ou Team-based Learning (TBL) e o Aprendizado Baseado em Problemas ou Problem-based Learning (PBL) são Metodologias Ativas de ensino que vêm sendo aplicadas em diversas disciplinas e proporcionam aos alunos a possibilidade de vivência de uma experiência do cotidiano profissional, o desenvolvimento da habilidade de trabalhar em equipe e a geração de soluções para as problemáticas apresentadas. Este artigo visa apresentar a utilização, resultados e benefícios dessas metodologias que foram aplicadas aos alunos do curso de Engenharia Civil da Universidade Potiguar. Para o TBL e o PBL foram utilizadas as metodologias Peer Instruction (PI) com o aplicativo "Plickers" para a leitura de $Q R$ codes entregues a cada aluno. Também é apresentado e discutido a aplicação de um Estudo de Caso, que é uma Estratégia de Ensino que também torna o ensino-aprendizado mais ativo. Para esse estudo, foi realizada uma visita técnica em um canteiro de obras localizado em Natal-RN, a fim de verificar o cumprimento das Normas Regulamentadoras. Essas aplicações se mostraram bastante eficazes, uma vez que, através de uma pesquisa, os alunos as avaliaram com um alto grau de satisfação.

Palavras-chave: Aprendizagem, Metodologias Ativas, TBL, PBL, Estudo de Caso.

\begin{abstract}
The Team-based Learning (TBL) and Problem-based Learning (PBL) are active teaching methodologies that have been applied in several disciplines and provide students with the possibility of experiencing a daily professional experience, the development of ability to work as a team and the generation of solutions to the problems presented. This paper aims to present the use, results and benefits of these methodologies that were applied to Civil Engineering students of Potiguar University. For TBL and PBL, the Peer Instruction (PI) methodology was used with the app "Plickers" to read QR codes delivered to each student. It is also presented and discussed the application of a Case Study, which is a Teaching Strategy that also makes teaching-learning more active. For the case study, a technical visit was carried out at a construction site located in Natal / RN, in order to
\end{abstract}


verify compliance with the Regulatory Rules. These applications were quite effective, since, through a survey, the students evaluated them with a high degree of satisfaction.

Keywords: Learning, Active Methodologies, TBL, PBL, Case Study.

\section{Resumen}

El aprendizaje basado en Equipos o Team-based Learning (TBL) y el aprendizaje basado en Problemas o Problem-based Learning (PBL) son metodologías activas de enseñanza que vienen siendo aplicadas en varias disciplinas y proporcionan a los estudiantes la posibilidad de vivenciar el día a día de un profesional, el desarrollo de destrezas para trabajar en equipo y la generación de soluciones para las problemáticas presentadas. Este artículo pretende presentar la utilización, resultados y beneficios de esas metodologías que fueron aplicadas e los alumnos del curso de Ingeniería Civil de la Universidad de Potiguar. Para el TBL y el PBL fueron usadas las metodologías Peer Instruction (PI) con el aplicativo "Plickers" para la lectura de códigos QR entregados a cada alumno. También se presenta y discute la aplicación de un caso de estudio, que corresponde a una Estrategia de Enseñanza que también torna la enseñanza-aprendizaje más activa y para eso fue realizada una visita técnica a una zona de obras localizado en Natal/RN, con el objetivo de verificar el cumplimiento de las Normas Reglamentarias. Esas aplicaciones se mostraron bastante eficaces, ya que, a través de una encuesta, los alumnos las evaluaron con un grado alto de satisfacción.

Palabras Claves: Aprendizaje, Metodologías Activas, TBL, PBL, Caso de Estudio. 


\section{Introdução}

A atual geração de estudantes está cada vez mais ativa e antenada e, ao mesmo tempo, focando menos tempo e atenção nas atividades acadêmicas e no aprendizado. Cada um desses estudantes precisa ser constantemente lembrado e conscientizado de que é o principal agente no seu processo de aprendizado. Aliado a isto, a conjuntura atual do sistema de educação tem tornado necessárias alterações na forma como os conteúdos são expostos, nas interações entre professor-aluno e nas maneiras de cobrança. Fatores como a baixa participação dos alunos, infraestrutura inadequada, professores desqualificados, carga-horária e componentes curriculares ineficientes, muitas distrações e as aulas tradicionais expositivas são geradores de alunos mecanizados e desinteressados em aprender, pois essas características do sistema de ensino e a falta de gana em querer aprender e descobrir não são adequadas a um aprendizado duradouro. Em uma sala de aula convencional, o professor apresenta os conteúdos, cabendo aos estudantes, se não procuram por si mesmos complementar o aprendizado, somente absorver o que é exposto. As aulas tradicionais não são capazes, por si só, de gerar sujeitos pensantes, proativos, criativos, bem relacionados, e que saibam lidar com problemas e resolvê-los.

Neste contexto, surgem as Metodologias Ativas que colocam o estudante como agente ativo do processo de aprendizagem dando um incentivo extra à busca pelo conhecimento e aplicação deste conhecimento, enquanto que o professor é o agente responsável por encaminhar e propor situações que suscitem observação, análise, raciocínio, interação, argumentação, entre outras características de um sujeito pensante e proativo. Nesse sentido, trocamse os cálculos mecânicos das Exatas por situações problema comuns do dia a dia de um profissional e espera-se que o estudante seja capaz de analisar e propor soluções aplicáveis ${ }^{11}$.

A utilização de Metodologias Ativas em Universidades vem evoluindo e tornando-se cada vez mais importantes para o aluno no processo de aquisição do conhecimento. Sendo assim, o curso de Engenharia Civil da Universidade Potiguar (UnP) do Rio Grande do Norte, através das disciplinas de Construção Civil I, Estrutura de Concreto Armado II, Fundações e Obras de Contenção e Segurança do Trabalho, vem implementando na ementa das respectivas disciplinas, novas metodologias de avaliação que dão alternativas e suporte para a garantia de novos conhecimentos de forma dinâmica e eficaz. Dentre as Metodologias Ativas empregadas, destacam-se: o Aprendizado Baseado em Equipe ou Team-based Learning (TBL) e o Aprendizado Baseado em Problemas ou Problem-based Learning (PBL).

O Aprendizado Baseado em Equipe foi usado por Larry Michaelsen ${ }^{1}$ na década de 70 em grandes grupos de alunos, dividindo-os em pequenos grupos para obter os benefícios do trabalho em equipe. Para o bom desenvolvimento da atividade, os estudantes desenvolvem estudos e leituras prévias, a fim de fornecer conhecimento e cooperar com sua equipe.

O Aprendizado Baseado em Problemas foi, inicialmente, usado para estudo de psicologia comportamental, na década de 1960. A metodologia visa produzir conhecimento em torno de projetos e problemas, em que o aluno terá que contribuir com uma parcela de conhecimento e, juntamente com seus colegas, chegar a um resultado em comum. Dessa forma, os estudantes são capazes de raciocinar, interagir, falar, escutar, debater, argumentar e construir um ideal com sua equipe.

O Estudo de Caso, por sua vez, é uma Estratégia de Ensino e enquadra-se em uma abordagem qualitativa e é frequentemente utilizado na coleta de dados em diversas áreas. Serve para responder questionamentos onde o pesquisador não tem muito controle sobre o fenômeno estudado.

Conforme a temática do estudo, o TBL e o PBL foram aplicados em algumas turmas de Engenharia Civil na disciplina de Segurança do Trabalho da UnP. Para o Estudo de Caso, 
verificou-se a aplicação do cumprimento das Normas Reguladoras (NR 18, NR 35, NR 17 e NR 6) em um canteiro de obra, onde foram realizadas entrevistas com os funcionários no canteiro de obra e registros fotográficos.

Para estudar e descrever a aplicação dessas metodologias e estratégia de ensino, este trabalho irá fazer uma breve revisão teórica sobre eles na seção 2 . Na seção 3 tem-se a apresentação de suas aplicações e breve discussão de seus resultados. E, finalmente, na seção 4 tem-se as considerações finais do trabalho.

\section{Metodologias Ativas e Estratégia de Ensino Aplicadas}

O modelo de ensino praticado nas instituições acadêmicas associado a uma geração de estudantes com atenção cada vez mais dispersa, tem colocado os processos de aprendizagem em segundo plano, visando mais os processos de instrução, com uma preocupação exacerbada em cumprir ementas e cargas horárias pré-estabelecidas e sem a preocupação em como o discente irá absorver e aplicar os conteúdos e assuntos ali ministrados. Diante desse cenário, a aplicação de Metodologias Ativas e novas estratégias de ensino como instrumentos catalisadores de mudança no paradigma ensino-aprendizado, onde tem como objetivo central o aprendizado e visam estabelecer um envolvimento entre o indivíduo e determinada situação, usando elementos que despertem o interesse, o engajamento e a eficiência na realização de uma determinada tarefa ou uma situação específica.

\subsection{O Aprendizado Baseado em Problemas (PBL)}

O PBL, como o próprio nome diz, consiste em trazer para o ambiente acadêmico problemas e casos reais previamente pensados e preparados, a fim de estimular os alunos a usar o raciocínio em conjunto com os assuntos já aprendidos em sala de aula na resolução de tais problemas/casos. A aplicação dessa metodologia se utiliza de pequenos grupos de alunos e de um professor tutor, que também é o responsável por aplicar a metodologia, e juntos iniciam a sequência de aprendizagem, que consiste na exploração do problema proposto, tentativa de solução, identificação de deficiência, priorização do que é necessário aprofundar em questão de conteúdo, aplicação deste estudo no questionamento do problema e, por fim, a avaliação que é efetuada sobre os conteúdos aplicados.

Dessa forma, Schmidt ${ }^{2}$ afirma que aprendizagem não é um processo de recepção e sim de construção de novos conhecimentos a partir do conhecimento prévio. Assim, os problemas provocam a oportunidade de aprender através da interação com a situação, como acontece na vida real, onde os conhecimentos aprendidos são acessados na memória e se ajustam para atender à demanda proposta.

\subsection{A Aprendizagem Baseada em Equipes (TBL)}

O TBL é um método de aprendizado onde equipes de estudantes são responsáveis pela construção e desenvolvimento do próprio conhecimento ${ }^{1}$.

$\mathrm{Na}$ aplicação do TBL os alunos são agrupados permanentemente e o conteúdo do semestre é dividido nas aulas, de acordo com Michaelsen ${ }^{1}$, buscando criar oportunidade e obter os benefícios do trabalho em pequenos grupos de aprendizagem, compostos por cinco a sete alunos $^{3}$. O prévio estudo pode incluir diversas atividades e a importância disto é que se o aluno não se prepara, ele não será capaz de contribuir com o seu grupo, dificultando a coesão entre eles. Previamente a cada aula, é elaborado pelo professor um material que os grupos deverão utilizar como fonte de estudo. Em seguida o professor deve propor uma atividade 
para os grupos que seja relacionada as ideias principais do conteúdo visto que deve ser feito em grupo, chegando a um consenso sobre a resposta da equipe. É interessante saber que os testes rápidos e de múltipla escolha, possibilitando uma ou mais respostas certas com o feedback imediato, constituem uma boa ferramenta para verificar a leitura prévia que é uma técnica defendida por Michaelsen ${ }^{1}$. Para o rápido feedback, pode ser utilizado uma ferramenta pedagógica chamada Peer Instruction (PI) que faz com que os alunos aprendam enquanto debatem, utilizando perguntas conceituais de múltipla escolha que são os ConcepTest.

Em cursos de Ciências Exatas, tem demonstrado ser uma maneira de envolver os alunos em sala de aula e em laboratório ${ }^{4-6}$. Utilizando o clickers/plickers (mecanismos de coleta eletrônica de respostas), que envolve cartões individuais e um aplicativo gratuito para smartphone ou tablet, utilizado para coletar as respostas de cada aluno através de $Q R$ codes.

O processo final inclui a apresentação do conteúdo de forma breve e específica permitindo ao professor esclarecer quaisquer equívocos que sejam explicitados durante o processo anterior. Ao aluno também é permitido fazer questionamentos sobre as respostas que erraram e tentar comprovar o porquê de ela não estar errada. Nessa última etapa são feitos trabalho, prova ou Estudo de Caso individuais para comprovação do conhecimento adquirido.

\subsection{Estudo de Caso}

O Estudo de Caso é uma Estratégia de Ensino que consiste de um método de investigação especialmente adequada quando procuramos compreender, explorar ou descrever acontecimentos e contextos complexos, nos quais estão envolvidos diversos fatores.

Há diferentes posicionamentos sobre as origens do Estudo de Caso. Um exemplo é Chizzotti $^{7}$, que define o Estudo de Caso como modalidade de pesquisa influenciada pelos estudos antropológicos de Malinowski e pela Escola de Chicago e, posteriormente, teve seu uso ampliado para o estudo de eventos, processos, organizações, grupos, comunidades, etc.

$\mathrm{Yin}^{8}$ define Estudo de Caso com base nas características do fenômeno em estudo e com base num conjunto de características associadas ao processo de recolha de dados e às estratégias de análise dos mesmos.

Para Ludke e Meda ${ }^{9}$, o Estudo de Caso se apresenta como uma estratégia de pesquisa, onde adota-se um caso, simples e específico ou complexo e abstrato e deve ser sempre bem delimitado. Uma estratégia que pode se assemelhar a outras, mas é também distinto, pois tem um interesse próprio, único, particular e que representa um potencial na educação.

De acordo com Goode e Hatt ${ }^{10}$, o Estudo de Caso vem ser um meio de organizar dados, preservando, do objeto estudado, o seu caráter unitário. Considera a unidade como um todo, incluindo o seu desenvolvimento (pessoa, família, conjunto de relações ou processos, etc.). Dessa maneira, a totalidade de qualquer objeto é uma construção mental, pois concretamente não há limites, se não forem relacionados com o objeto de estudo da pesquisa no contexto em que será investigada. Então, é por meio do Estudo de Caso que se pretende investigar, como uma unidade, as características importantes para o objeto de estudo da pesquisa.

\section{Relatos de Experiências}

Como objeto de estudo da pesquisa, analisou-se dois casos de aplicação de Metodologia Ativa e um Estudo de Caso na Universidade Potiguar. As Metodologias Ativas e o Estudo de Caso foram aplicadas, pelo professor responsável, na disciplina de Segurança do Trabalho.

\subsection{Caso 1: Aplicação do PBL}


Foi aplicado o PBL em algumas turmas do curso de Engenharia Civil da UnP no semestre de 2016.1 e com essas turmas foram feitas análises de satisfação quanto à aplicação do método e análise do desempenho por parte dos alunos e de suas respectivas turmas. $\mathrm{O}$ PBL passou a fazer parte da nota do aluno, representando uma parte da nota total.

\subsubsection{Metodologia Aplicada}

Para dar início à aplicação do PBL, os alunos foram organizados em grupos de quatro a sete pessoas, sendo esta organização feita de forma aleatória usando o Excel. Na etapa de preparação para cada aula, o professor elaborou um material usado pelos grupos como fonte de estudo e então foi feito um debate em sala sobre o conteúdo visto para mais esclarecimentos, cerca de 20 a 30 minutos do tempo de aula.

Em seguida, o professor propunha, para os grupos, uma atividade que fosse relacionada às ideias principais do conteúdo visto. Os alunos responderam aos Concep Test utilizando um mecanismo de resposta imediata denominado Plickers, que através de cartões individuais e um aplicativo gratuito para smartphone ou tablet, recebe as respostas através de leitura de $Q R$ codes, conforme Fotografia 1.

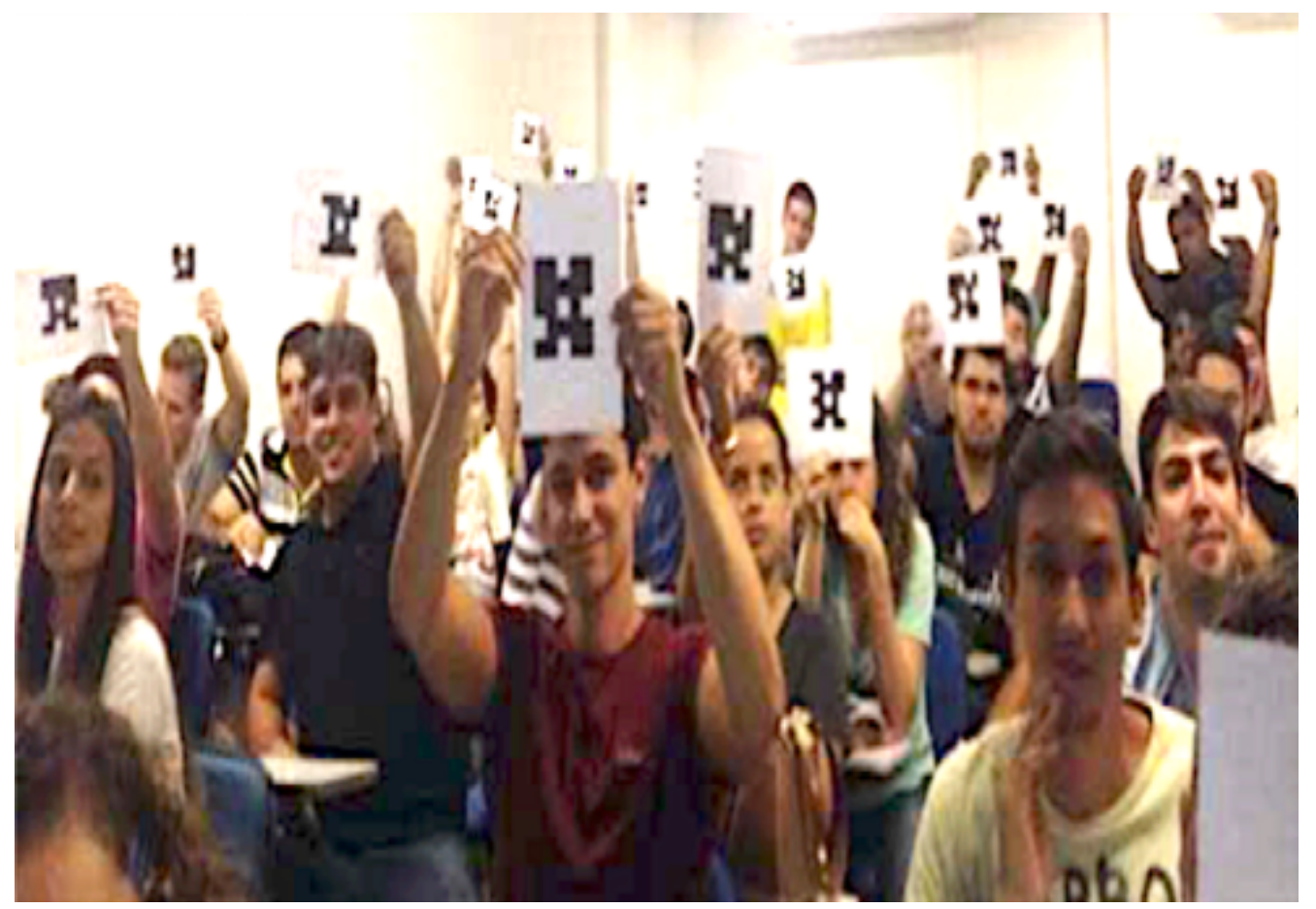

Fotografia 1. Coleta de resposta das equipes com leitura do $Q R$ code através do Plickers.

Logo após os alunos responderem à questão exposta, o professor tem acesso às respostas dadas e ao resumo do desempenho da turma. A partir desses resultados o grupo podia discutir com o professor sobre as questões que erraram, sobre o porquê destas estarem incorretas e cada aluno tinha a oportunidade de apresentar argumentos para provar o contrário.

O processo final permite ao professor apresentar o conteúdo de forma breve e específica para esclarecer quaisquer equívocos que sejam explicitados durante o processo anterior. Ao longo do semestre os conhecimentos foram acumulados e avaliados em provas individuais. 


\subsubsection{Resultados e Discussões}

Foi aplicado o PBL em algumas turmas do curso de Engenharia Civil da UnP no semestre de 2016.1 e com essas turmas foram feitas análises de satisfação quanto a aplicação do método e análise do desempenho por parte dos alunos e de suas respectivas turmas. O PBL passou a fazer parte da nota do aluno, representando uma parte da nota total. Os objetivos propostos pelo trabalho levaram à análise temática das respostas de questionários, estruturado em forma de pesquisa de satisfação e conhecimento das Metodologias Ativas e análise de dados subsequentes. Foi fornecido um questionário aos alunos, para avaliação da aplicação do PBL. No questionário constavam perguntas, onde os alunos marcavam suas repostas da seguinte forma: 1 - PÉSSIMO; 2 - RUIM; 3 - RAZOÁVEL; 4 - BOM; 5 EXCELENTE. O questionário utilizado para avaliação da satisfação quanto a metodologia consistiu das perguntas apresentadas no Quadro 1.

Quadro 1. Questionário de avaliação.

\begin{tabular}{|ll|}
\hline Questão 1 & Como você avalia a metodologia? \\
Questão 2 & O que achou desta nova proposta de aula? \\
Questão 3 & Esta metodologia contribuiu para absorção do conteúdo? \\
Questão 4 & Você já conhecia esta metodologia? \\
\hline
\end{tabular}

No Gráfico 1, é apresentado o resultado da primeira pergunta. Pode-se observar que $51 \%$ dos alunos entrevistados julgaram a metodologia boa e $44 \%$ julgaram como excelente. Logo, a metodologia foi muito bem avaliada pelos alunos.

No Gráfico 2, é apresentado o resultado da segunda pergunta. Observa-se que $39 \%$ dos alunos entrevistados julgaram o novo tipo de aula bom e $54 \%$ julgaram como excelente. De acordo com os dados, o tipo de aula advindo desta nova metodologia teve uma boa aceitação por parte dos alunos.

No Gráfico 3, é apresentado o resultado da terceira pergunta. Pode-se observar que $49 \%$ dos alunos entrevistados julgaram a metodologia boa e $44 \%$ julgaram como excelente. Assim, na opinião dos estudantes, a metodologia se mostrou uma eficiente ferramenta para absorção do conteúdo.

No Gráfico 4, é apresentado o resultado da quarta pergunta. Com base nos dados, observa-se que 58,54\% dos alunos não conheciam a metodologia ativa, e 41,46\% conheciam.

Como avaliação da aplicação do PBL também pode-se apresentar uma amostra do rendimento dos alunos nos questionários aplicados pelo professor durante o semestre. Nos Gráficos 5, 6 e 7 são apresentados os resultados de alguns PBL's realizados pelo professor e o desempenho da turma. Foram respondidas 9 (nove) perguntas, em média. Os Gráficos 5 , 6 e 7 trazem o percentual de acertos dos alunos em cada questão e os resultados por turma.

Diante dos dados coletados verificou-se que, de forma geral, o desempenho dos alunos analisados foi mais que satisfatório e o nível de aprendizado foi elevado, ao se considerar não somente os resultados dos testes, mas também o envolvimento dos estudantes no trabalho em grupo, a dinâmica das atividades, a interação com o conteúdo apresentado, o surgimento de questionamentos e o posterior debate para saná-los. A metodologia de Aprendizado Baseado em Problemas se mostrou muito eficaz em direcionar os estudantes ao estudo prévio à aula, incentivando-os a se aprofundar nas opções que o conteúdo apresenta e não somente no que seria exposto em sala em uma aula tradicional. 


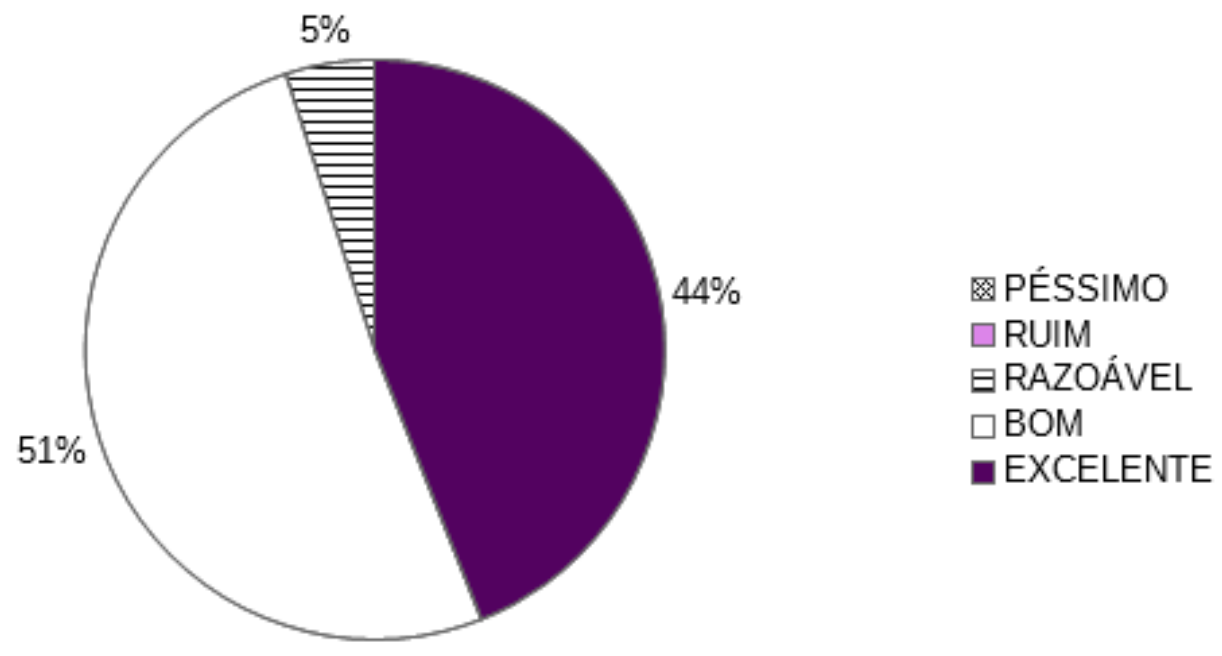

Gráfico 1. Satisfação dos alunos em relação a metodologia.

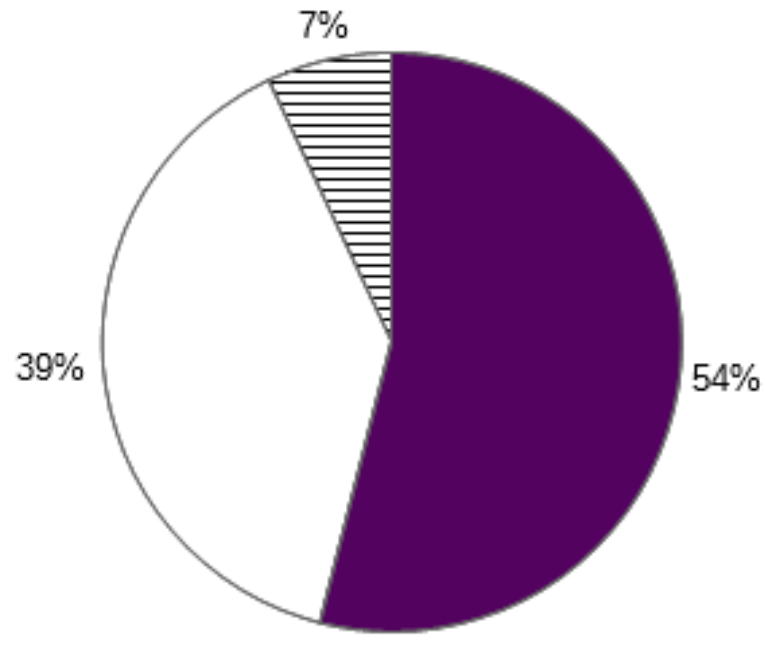

図PÉSSIMO

$\square$ RUIM

曰RAZOÁVEL

$\square$ BOM

- EXCELENTE

Gráfico 2. Satisfação dos alunos em relação a nova proposta que a metodologia traz. 


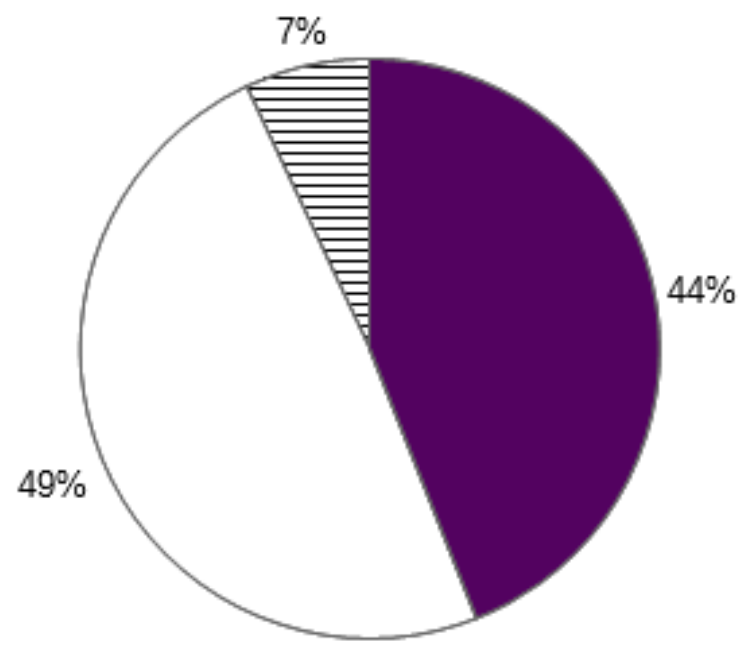

図PÉSSIMO

$\square$ RUIM

曰RAZOÁVEL

$\square$ BOM

EXCELENTE

Gráfico 3. Satisfação dos alunos em relação a absorção do conteúdo.

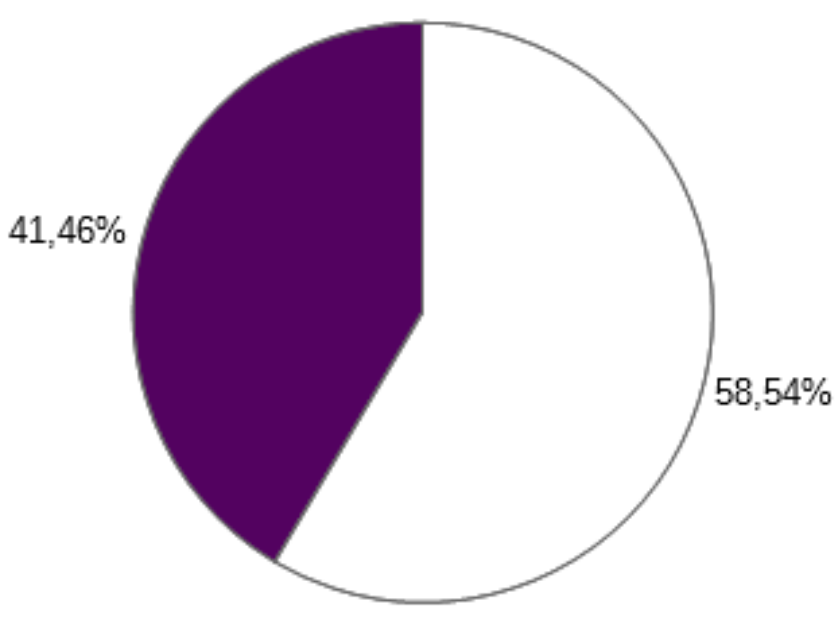

- SIM $\square N$ ÃO

Gráfico 4. Conhecimento dos alunos perante a metodologia. 


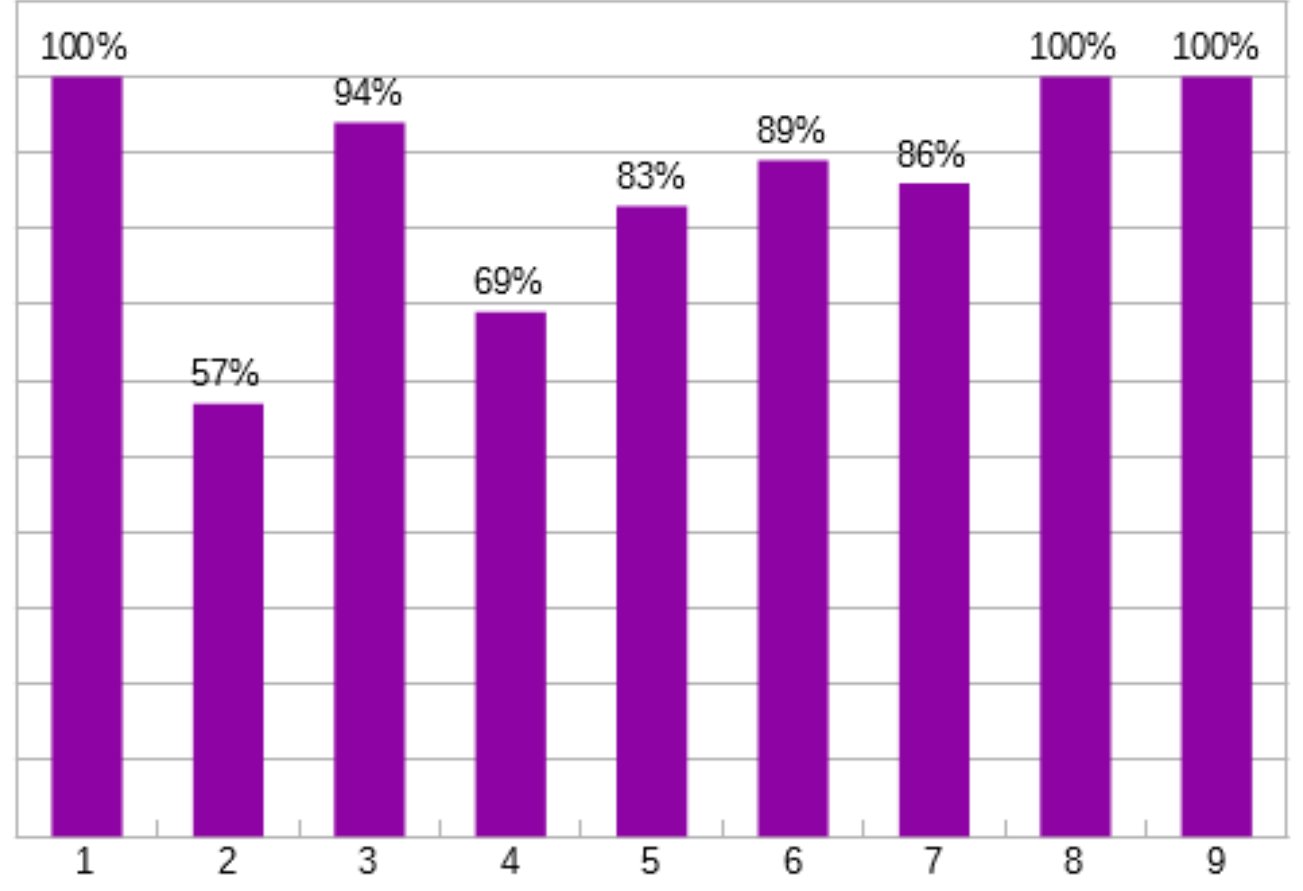

Gráfico 5. Conhecimento dos alunos perante a metodologia (Acertos: ECI 5TB - 13.05).

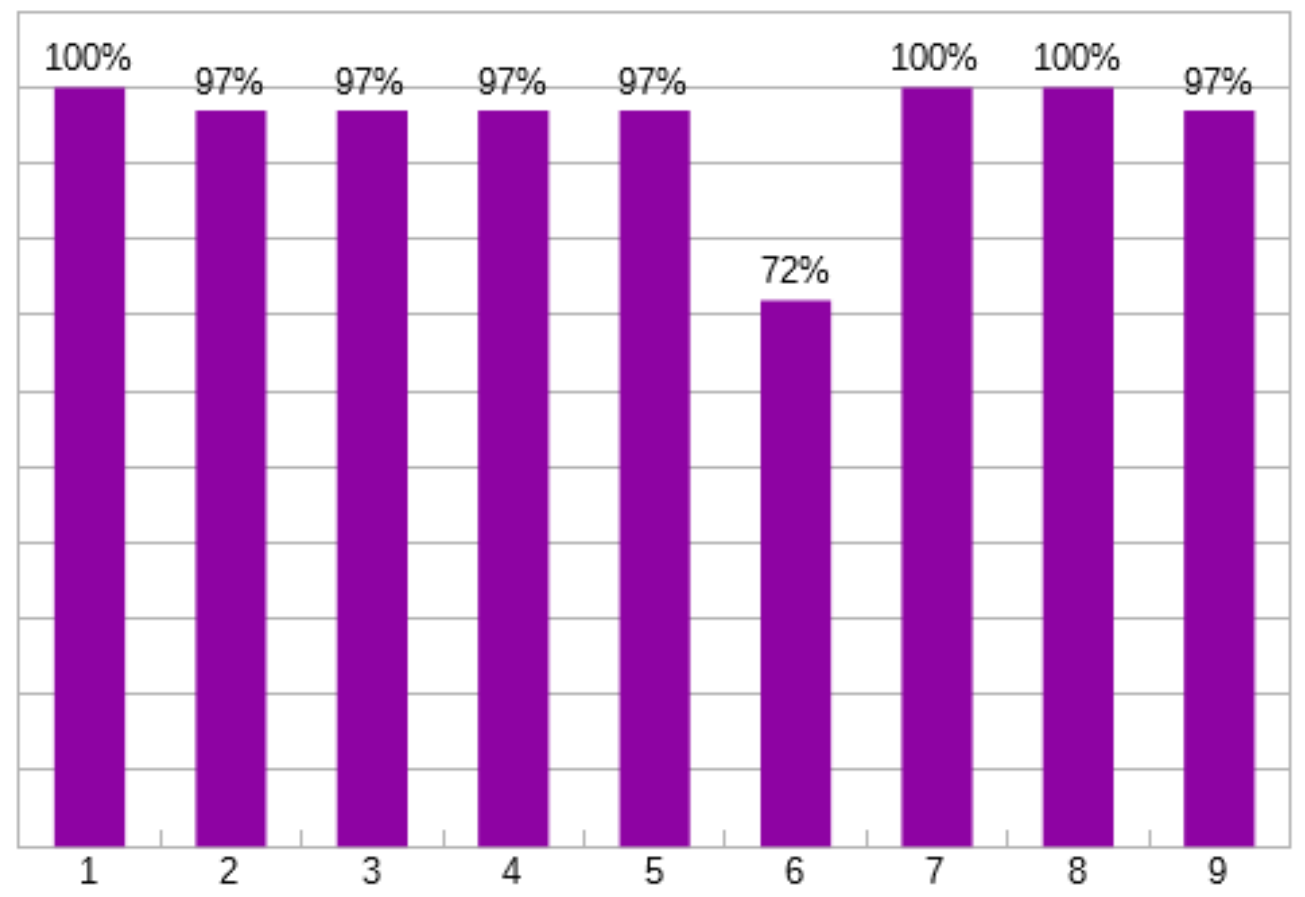

Gráfico 6. Conhecimento dos alunos perante a metodologia (Acertos: ECI 5TA - 03.05). 


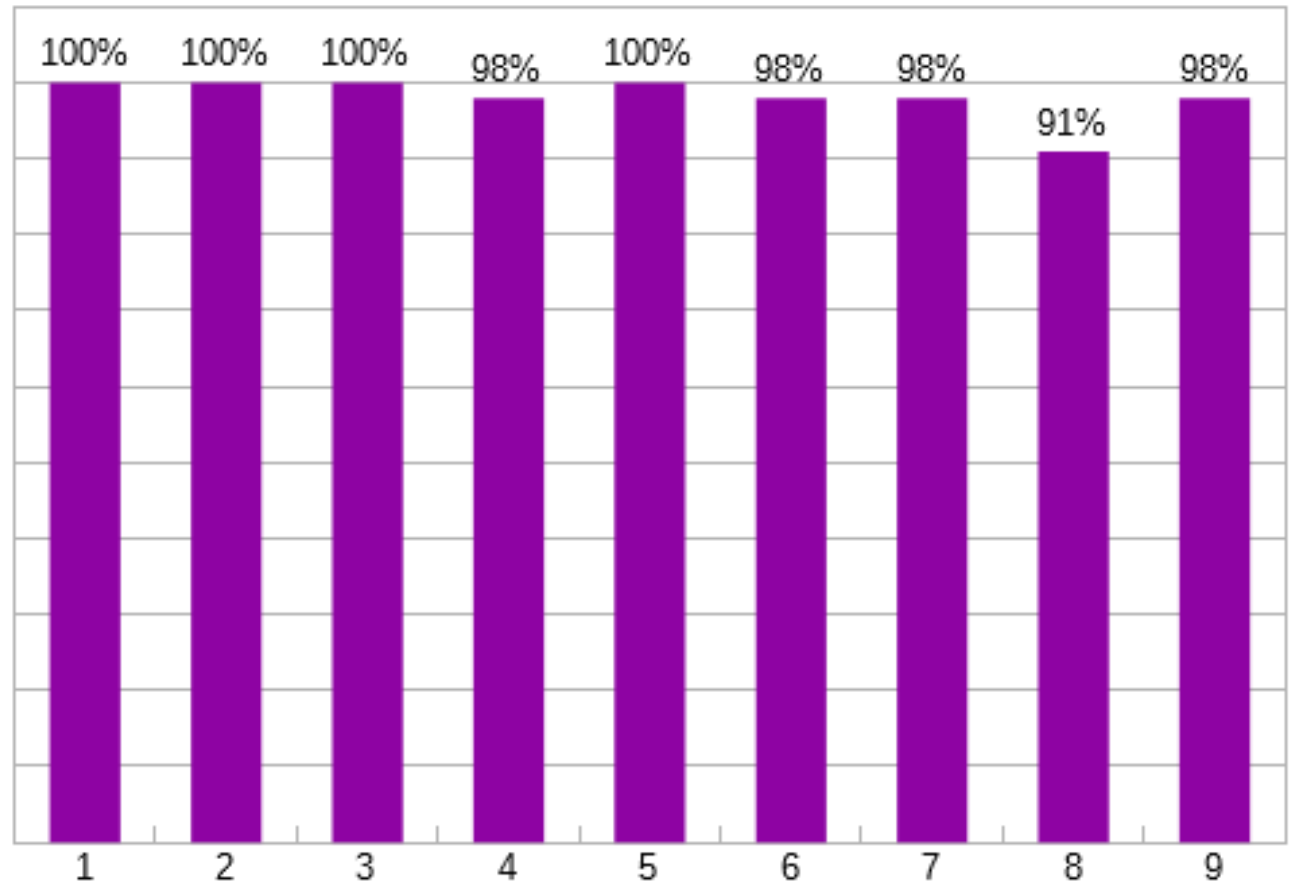

Gráfico 7. Conhecimento dos alunos perante a metodologia

(Acertos: ECI 8TA - 25.05).

\subsection{Caso 2: Aplicação de TBL na Universidade Potiguar}

A Universidade Potiguar aplicou o TBL nos cursos de Engenharia Civil das turmas de $5^{\mathrm{a}}$ e $8^{\mathrm{a}}$ série no semestre de 2016.1, na disciplina de Segurança do Trabalho, com um total de 112 alunos avaliados e com essas turmas foram feitas análises de satisfação quanto a aplicação do método e análise do desempenho por parte dos alunos e de suas respectivas turmas. O TBL passou a fazer parte da nota do aluno, representando $70 \%$ da nota total no referido semestre.

\subsubsection{Metodologia Aplicada}

A metodologia utilizada para aplicação do Aprendizado Baseado em Equipes (TBL) foi similar à usada na aplicação do PBL. Assim, antes de começar as etapas os grupos foram formados pelo professor com a utilização de sorteio aleatório pelo Excel, onde cada grupo tinha entre 4 e 7 estudantes.

Na etapa de preparação para cada aula, foi elaborado pelo professor um material que os grupos deviam utilizar como fonte de estudo e, na aula, era feito um debate sobre o conteúdo visto para mais esclarecimentos, cerca de 20 a 30 minutos do tempo de aula. Em seguida o professor propunha uma atividade para os grupos relacionada as ideias principais do conteúdo, realizada com o uso de Peer Instruction (PI), permitindo apenas uma resposta correta por questão. Assim, como no caso do PBL, os alunos responderam aos Concep Tests utilizando o Plickers. Em resumo, a dinâmica e o desenrolar das aulas ocorreram de formas similares às da aplicação do PBL, mas a construção e apresentação dos conteúdos eram feitas 
pelos estudantes a partir do estudo prévio e da discussão em grupo, sendo que o professor tinha acesso imediato às respostas dos estudantes aos Concep Tests.

\subsubsection{Resultados e Discussões}

Os objetivos propostos pelo trabalho levaram à análise de questionário aplicado para quantificar e qualificar a satisfação dos alunos acerca da proposta de metodologia ativa. $\mathrm{Na}$ hora de aplicação do TBL, foi fornecido um questionário aos alunos, onde eles marcavam suas repostas da seguinte forma: 1 - PÉSSIMO; 2 - RUIM; 3 - RAZOÁVEL; 4 - BOM; 5 - EXCELENTE. Este questionário continha as mesmas perguntas usadas para avaliar a satisfação dos alunos quanto ao PBL.

No Gráfico 8, é apresentado o resultado da primeira pergunta sobre a aplicação do TBL. Pode-se observar que $44 \%$ dos alunos entrevistados julgaram a metodologia boa e $48 \%$ a julgaram excelente. Portanto, a metodologia teve um retorno favorável dos alunos, o que é evidenciado por sua boa avaliação.

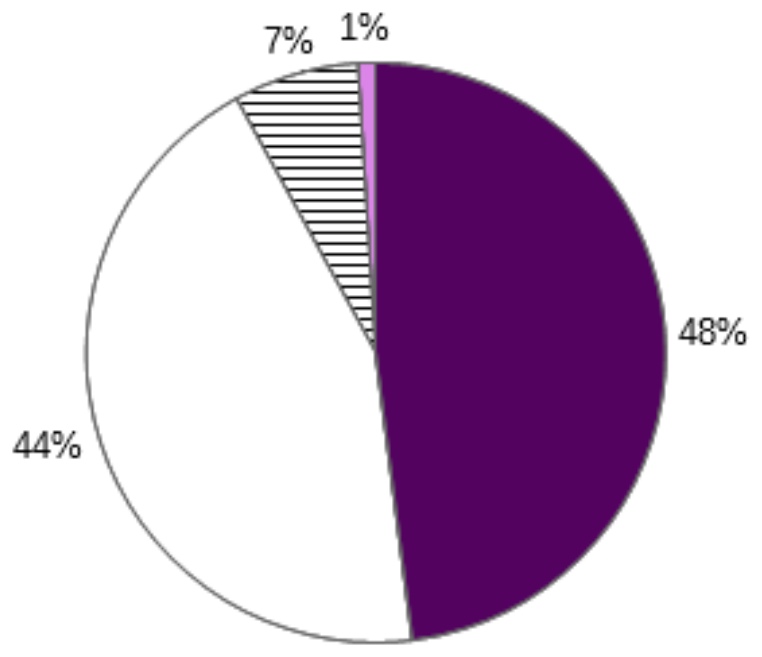

図PÉSSIMO

$\square$ RUIM 日RAZOÁVEL $\square \mathrm{BOM}$ EXCELENTE

Gráfico 8. Satisfação dos Alunos em relação a metodologia.

No Gráfico 9, é apresentado o resultado da segunda pergunta. Observa-se que $45 \%$ dos alunos entrevistados julgaram a metodologia boa e $50 \%$ julgaram como excelente. Baseado nos dados, percebe-se que a metodologia foi bem aceita pelos alunos.

No Gráfico 10, é apresentado o resultado da terceira pergunta. Pode-se observar que $30 \%$ dos alunos entrevistados julgaram a metodologia boa e $65 \%$ julgaram como excelente. Assim, conclui-se que o TBL se mostrou eficiente para que os alunos tivessem a devida absorção do conteúdo.

No Gráfico 11, é apresentado o resultado da quarta pergunta. Com base nos dados, observa-se que 83,93\% dos alunos não conheciam a metodologia ativa, e 16,07\% conheciam. 


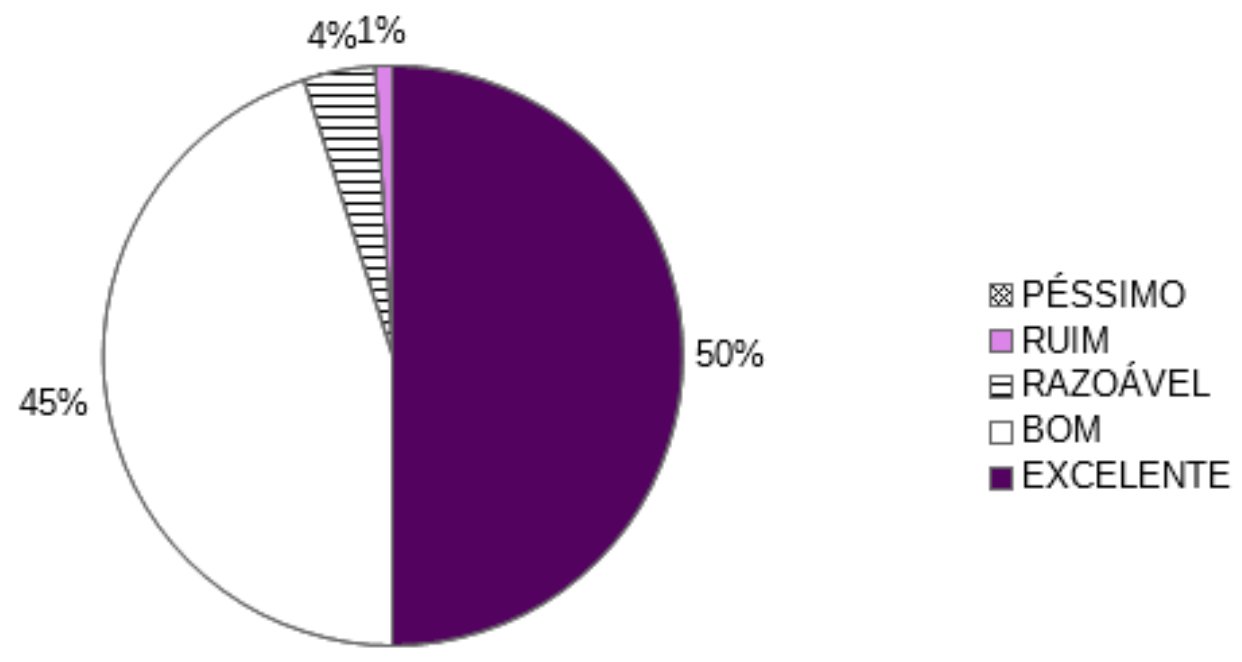

Gráfico 9. Satisfação dos Alunos em relação a metodologia.

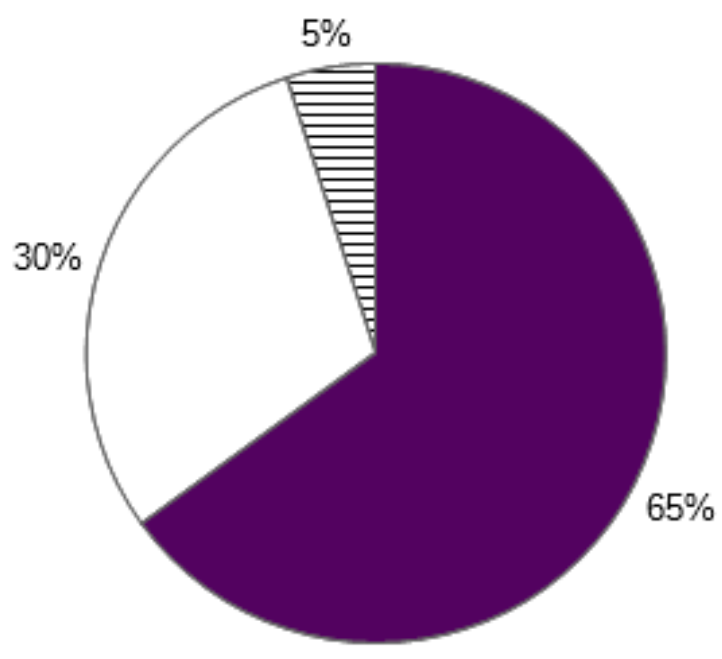

図 PÉSSIMO

$\square$ RUIM

曰RAZOÁVEL

$\square$ BOM

- EXCELENTE

Gráfico 10. Satisfação dos Alunos em relação a absorção do conteúdo. 


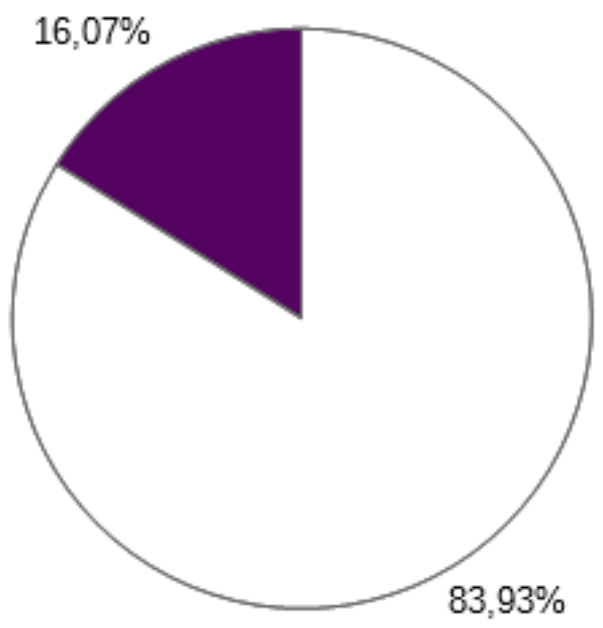

Gráfico 11. Conhecimento prévio dos alunos acerca da metodologia.

Os resultados obtidos na avaliação da aplicação do TBL mostraram uma boa aceitação deste por parte dos estudantes e que o TBL se mostrou bem eficiente em vários aspectos. Percebe-se, desta forma, que alternativas que busquem uma dinamização do conteúdo abordado em sala de aula tem uma boa recepção dos alunos.

\subsection{Caso 3: Aplicação de Estudo de Caso na Universidade Potiguar}

Para o Estudo de Caso fez-se necessário conhecimento prévio das normas regulamentadoras de segurança que foram a fundamentação para a análise qualitativa do Estudo de Caso. As normas são NR 17 "Ergonomia", a NR 18 "Condições e Meio ambiente de Trabalho na Indústria da Construção", a NR 35 "Trabalho em Altura" e a NR 6 "Equipamentos de Proteção Individual - EPI", essas duas últimas relacionadas a NR 18.

\subsubsection{Metodologia Aplicada}

O Estudo de Caso trouxe uma abordagem qualitativa, sendo que a análise dos dados coletados aproximou-se da análise textual discursiva. Para alcançar o objetivo, foram aplicados questionários com perguntas abertas a funcionários da obra tanto no setor administrativo quanto no de operações.

Foram realizadas três etapas no Estudo de Caso. A primeira foi a criação do questionário de acordo com as normas a serem avaliadas. A segunda foi a visita técnica à obra com registro fotográfico e entrevista. E a terceira etapa foi a análise dos dados obtidos.

É importante ressaltar que, na segunda etapa, a entrevista foi dividida em duas partes. Na primeira parte a entrevista foi feita com os funcionários do setor administrativo na qual 
observou-se as visões de cada um, como também, a análise técnica a respeito da importância das normas reguladoras e da sua funcionalidade na empresa. Na segunda parte, a entrevista foi feita com os operários de campo e verificou-se o cuidado que cada um tem em fazer uso dos EPI's.

\subsubsection{Resultados e Discussões do Estudo de Caso}

A construção, objeto deste Estudo de Caso, já em fase de acabamento, contava com aproximadamente 50 operários trabalhando em diversas funções. Segundo o levantamento, a edificação possuía PCMAT (Programa de Condição de Meio Ambiente de Trabalho na Indústria de Construção) atualizado e PCMSO (Programa de Controle Médico de Saúde Ocupacional), cumprindo o que exige a Norma regulamentadora. Além disso, todos os dias após o fim do expediente acontecia o DDS (diálogo diário de segurança). Na parte da entrevista, realizou-se um levantamento de dados, por meio da aplicação de um questionário baseado nas normas já citadas. Foram aplicados questionários diferentes para os funcionários administrativos e para os funcionários da obra. Estes questionários estão reproduzidos nos Quadros 2 e 3.

Quadro 2. Questionário - Funcionários da administração.

\begin{tabular}{|ll|}
\hline Questão 1 & $\begin{array}{l}\text { Qual a sua opinião profissional acerca das Normas } \\
\text { Regulamentadoras de Segurança? }\end{array}$ \\
Questão 2 & $\begin{array}{l}\text { Existe alguma limitação imposta pela empresa em } \\
\text { aplicá-las? }\end{array}$ \\
Questão 3 & $\begin{array}{l}\text { Qual a importância que a empresa dá para a apli- } \\
\text { cação das NR's na obra }\end{array}$ \\
Questão 4 & $\begin{array}{l}\text { Quais os parâmetros utilizados pela empresa na hora } \\
\text { da compra dos EPI's, tendo em vista que muitas em- } \\
\text { presas não prezam pela qualidade e sim pelo custo? } \\
\text { Questão 5 }\end{array}$ \\
Como é a assiduidade dos profissionais da obra nos \\
DDS? \\
Quais os suportes que a empresa oferece ao fun- \\
cionário em caso de acidentes? \\
Com relação a ergonomia, o que a empresa busca \\
fazer para evitar problemas como "LER/DORT"?
\end{tabular}

Quadro 3. Questionário - Funcionários da obra.

Questão 1 Qual a sua opinião acerca do uso de EPI'S?

Questão 2 Já aconteceu algum acidente na obra por não uso do EPI? Se sim, qual foi o suporte que a empresa ofereceu?

Questão 3 Você sente dores ao fim do dia, por esforço repetitivo? Se sim, onde?

Questão 4 Já faltou trabalho por algum problema decorrente do esforço no trabalho?

De acordo com a entrevista pôde-se verificar que os mesmos não se queixavam de nenhuma doença aparente decorrente do trabalho - LER ou DORT. As queixas apresentadas eram a respeito de incômodos na coluna, justificados pelo cansaço e fadiga depois de um 
dia de trabalho. Assim, não foi constatada nenhuma intervenção ergonômica em favor da prevenção da fadiga. Durante um período da obra, um desses operários reclamou ao Engenheiro responsável que estava sentindo dores na coluna decorrente ao carregamento de peso, prontamente o Engenheiro solicitou que outro trabalhador o ajudasse, minimizando assim possíveis problemas de saúde ao operário.

Todos os trabalhadores contavam com um acompanhamento psicológico e, principalmente, com um treinamento diário (DDS) dado pelo técnico de segurança responsável por treinar e acompanhar as atividades diárias no local. Ao longo da vistoria notou-se que todos os trabalhadores estavam utilizando corretamente todos os EPI'S (botas, capacete, protetor auricular, luvas, máscaras, cintos - em caso de altura) necessários e exigidos por Norma.

Na segunda parte da visita foi feita a comparação entre as normas citadas e os registros fotográficos. Pôde-se observar que o canteiro de obra estava bem dimensionando no terreno e estava respeitando todas as divisões que solicita a NR-18. Como a obra estava em fase de conclusão algumas partes já haviam sido extintas.

Verificou-se que as instalações da obra apresentavam portas de acesso que impediam o devassamento e que foram construídas de modo a manter o resguardo conveniente, não estando ligadas diretamente com os locais destinados às refeições. A iluminação era adequada e estava situada em locais de fácil e seguro acesso. Quanto as instalações sanitárias, verificouse que estavam em perfeito estado de conservação e higiene. Pôde-se constatar que nessa obra havia mais do que o necessário requerido pela NR.

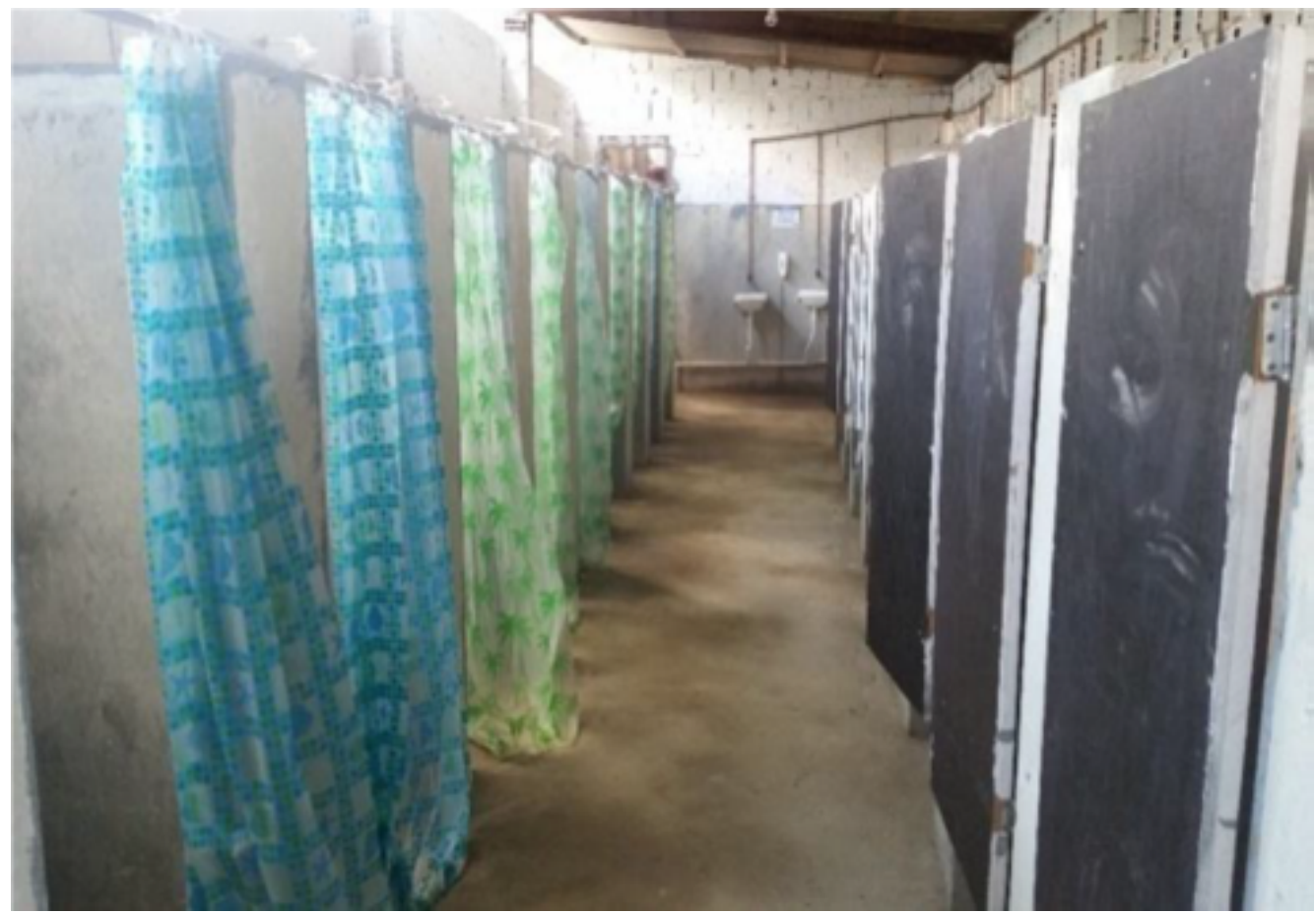

Fotografia 2. Banheiro conforme regulamenta a NR 18.

Verificou-se também que a obra não dispunha de ambulatório mesmo possuindo mais de 50 trabalhadores. A construção não possuia alojamento, lavanderia e área de lazer porque não havia trabalhadores morando na obra. 
A utilização dos equipamentos de proteção individual (EPI) e coletivo (EPC) era obrigatória e não foram encontrados indícios de resistência por parte dos trabalhadores, pois todos reconheciam a sua função em proteger e diminuir o impacto de acidentes que por ventura poderiam acontecer. A empresa disponibilizava, trocava e fazia a higienização dos EPI.

Havia um cuidado e medidas de proteção contra quedas de altura seguindo as exigências da NR-18 e também aparada pela Norma Regulamentadora 35 (Trabalho em Altura).

Dessa maneira, foi realizado um parecer técnico indicando que apesar de encontrar casos pontuais fora das normas estabelecidas, a maior parte dos requisitos haviam sido cumpridos e para os casos negativos encontrados havia, em contrapartida, um tratamento para o problema em andamento. O Parecer considerou apto para o trabalho o canteiro em questão.

Em suma, ao comparar as normas com as respostas da entrevista e os registros fotográficos, foi observado que a obra escolhida e vistoriada para a execução do estudo, apontou pontos importantes que enaltece a organização e cuidado da empresa com os seus trabalhadores. O ambiente foi vistoriado e pôde-se ver que há toda uma logística que vem a proporcionar um ambiente de trabalho limpo, saudável e com um risco menor de ocorrência de acidente.

Quanto às discussões oriundas desse Estudo de Caso, pode-se observar que essa Estratégia de Ensino se mostrou eficaz para os alunos envolvidos no estudo, possibilitando a compreensão e fixação dos conhecimentos adquiridos de forma a aplicá-los na vida prática como Engenheiros. Portanto, o Estudo de Caso se mostrou apto para aplicação, podendo ainda ser verificado, em pesquisas futuras, se há melhoria de desempenho dos alunos que utilizam o Estudo de Caso nas disciplinas. Abaixo temos depoimentos de alguns alunos que participaram do trabalho de Estudo de Caso.

"Assistir uma aula nunca deixará de ser válido e importante. Entretanto, a possibilidade de visualizar o conteúdo e lidar diretamente com ele tem se mostrado muito interessante, ainda mais com o estudo de um caso real. Ir ao local, lidar com os funcionários e enxergar as vivências de lá é realmente de grande valia e de grande aprendizado" (Aluno 1, 2016).

"Creio que a inserção de novas metodologias de ensino sejam excelentes. Tive o privilégio de evidenciar algumas dessas metodologias como forma de avaliação para o semestre que curso. A dinâmica na sala se torna outra, e até as disciplinas mais teóricas, que causam muitas das vezes um desconforto nos estudantes de Engenharia, tornam-se mais interessantes. Através do estudo, constatamos a eficiência e eficácia das Metodologias Ativas. Creio que estudos nessas metodologias são bastante relevantes, pois fazem com que novas metodologias sejam implementadas e as antigas reformuladas e melhoradas." (Aluno 2, 2016).

"A Metodologia Ativa de aprendizagem do Estudo de Caso, apresenta-se de forma bastante eficaz no âmbito acadêmico. Pois possibilita um contato mais parecido com a realidade a ser vivenciada pelo discente após a conclusão do curso, além de estimular o aluno a solucionar problemas reais." (Aluno 3, 2016).

"O Estudo de Caso foi muito importante, para atrelar o conhecimento a prática. Ao visitar a obra pude constatar a aplicação das NR's e avaliar se estavam ou não cumprindo o que exige as normas regulamentadoras. Concluí que quando a aula deixa de ser tão mecanizada, com vários slides e podemos de alguma maneira aplicar o que estamos aprendendo, a matéria fica mais interessante." (Aluno 4, 2016). 
"A metodologia de Estudo de Caso, como método de aprendizado é de grande importância para se adquirir conhecimento de forma dinâmica e eficiente, tendo em vista os diversos meios que possibilitam adquirir o mesmo. Agregar a metodologias como o Estudo de Caso é uma das diversas formas de garantir aprendizado contínuo, dinâmico e eficaz." (Aluno 5, 2016).

"O Estudo de Caso se mostrou eficaz no meu aprendizado, pois através dele pude fazer reflexões práticas do que aprendi, sem contar na confiança que obtive como futura profissional na utilização dos conhecimentos adquiridos." (Aluno 6, 2016).

Com base nos resultados, é possível inferir que o método de Estudo de Caso, como estratégia ativa de ensino, mostrou-se bastante satisfatório. Pois, além de permitir uma melhor compreensão e concretização dos conhecimentos teóricos, seja por parte do docente pesquisador ou do aluno, é uma ferramenta crucial na resposta de questionamentos que dependem de fatores externos. Portanto, provou-se potencialmente eficaz.

Sobre o Estudo de Caso aqui exposto, pôde-se constatar que a Construtora em estudo mostrou-se eficiente em todo o seu planejamento, organização e preocupação em manter um ambiente seguro, e, assim, garantir que as atividades fossem executadas com segurança e de acordo com as normas vigentes. Apesar de ter se mostrado falha quanto à preparação para realizar tratamento de pequenos acidentes, a empresa ainda assim apresentou-se eficiente, pois possuía uma boa estrutura quanto a prevenção de acidentes, desde o dimensionamento do canteiro de obras até o que diz respeito à proteção individual, possibilitando concluir que, como as causas dos acidentes de trabalho estão ligadas com as condições ambientais a que estão expostos os trabalhadores e ao aspecto psicológico, seu cuidado nesses aspectos deve ter diminuído a incidência de acidentes e, por conseguinte, a necessidade de tais tratamentos.

\section{Considerações Finais}

Pesquisas envolvendo Metodologias Ativas para sala de aula são muito importantes, pois aprimora-se as antigas e desenvolve-se novas, visando sempre estimular e melhorar o aprendizado, formando profissionais de excelência, já que a forma com que os alunos absorvem os conteúdos influencia de forma direta em suas vidas profissionais.

Tendo em vista os resultados obtidos com os dados coletados e, somando-se aos fatores indiretos relacionados com as Metodologias Ativas e o Estudo de Caso aplicados, tais como visualização de uma problemática, interação em grupo, debate, questionamento e dinamicidade, o artigo coletou bons resultados, uma vez que o desempenho dos alunos avaliados se mostrou satisfatório.

As metodologias e a estratégia de ensino aplicados mostraram-se excelentes ferramentas da relação ensino-aprendizado, uma vez que influenciaram os alunos a estudarem previamente às aulas, provocaram discussões saudáveis em sala, desenvolveram habilidades de pesquisa e visualização de problemas, inserindo os estudantes nos seus próprios processos de aprendizagem. Basicamente, usando esses meios, o aluno torna-se parte atuante e o grande responsável pelo seu conhecimento.

Devemos ressaltar que essas metodologias dependem de um conhecimento prévio e, embora incentivem os estudantes ao estudo fora de sala de aula e anteriormente às aulas, não tendem a ser efetivas no aprendizado de componentes curriculares iniciais dos cursos de graduação. Por outro lado, a participação de estudantes no início de seus cursos universitários em projetos e experimentos que fazem uso de PBL, TBL ou Estudo de Caso, em conjunto 
com estudantes mais avançados no curso, pode despertar nos iniciantes a vontade e o desejo por adquirir os conhecimentos necessários à sua formação e a perceber que eles mesmos são os autores e responsáveis por seu aprendizado e formação. Isto nos permite concluir que as Metodologias Ativas deveriam ser utilizadas para estudantes em componentes curriculares iniciais do curso apenas como um complemento e incentivo ao aprendizado, não substituindo as aulas expositivas que devem sempre incentivar e propor o estudo e pesquisa fora de sala de aula.

\section{Agradecimentos}

Aos professores Hugo E. S. Câmara (UNP) e Everlânia M. da Silva (UNP), e aos alunos que participaram da pesquisa por seu apoio na elaboração desse trabalho.

\section{Referências}

1. MICHAELSEN, L. K. Getting Started with Team Based Learning. In: Michaelsen LK, Knight A B, Fink L D, editors. Team-Based Learning: A Transformative Use of Small Groups. Westport: Praeger, 2002.

2. SCHIMIDT, H. G. Foundations of problem-based learning: some explanatory notes. Medical Education. Medford, v. 27, n. 5, 1993.

3. BURGUESS, A.W.; MCGREGOR, D.M.; MELliS, C.M. Applying established Guidelines to team-based learning programs in medical schools: A systematic review. Revista Academic Medicine, no. 4, pp.1-11, 2014.

4. CROUCH, C. H.; MAZUR, E. Peer Instruction: Ten years of experience and results. American Journal of Physics, no. 69, pp.970-977, 2001.

5. CROUCH, C. H.; WATKINS, J.; FAGEN, A. P.; MAZUR, E. Peer Instruction: Engaging students one-on-one, all at once. Research-based Reform of University Physics. 2007 .

6. LASRY, N. Clickers or Flashcards: Is There Really a Difference?. American Journal of Physics, no. 46, pp. 242-244, 2008.

7. CHIzZOTTI, A. Pesquisa em Ciências Humanas e Sociais. 2a ed, São Paulo: Cortez, 1995.

8. YIN, R. K. Estudo de Caso: Planejamento e Métodos. Porto Alegre: Bookman, 2015.

9. LUDKE, M.; MEDA, A. Pesquisa em educação: abordagens qualitativas. São Paulo, SP: EPU: 1986.

10. GOODE, W.J.; HATT, P.K. Métodos em pesquisa social. São Paulo, SP: Companhia Editora Nacional, 1979.

11. BORGES, T.; ALENCAR, G. Metodologias ativas na promoção da formação crítica do estudante: o uso das Metodologias Ativas como recurso didático na formação crítica do estudante do ensino superior. Cairu em Revista. no. 4, pp. 119-143, 2014. 